\title{
EXPERIMENTAL AND THEORETICAL INVESTIGATIONS OF SPIGOT CONNECTIONS UNDER CYCLIC LOADING
}

\author{
Mutasim Abdel-Jaber ${ }^{1}$, Robert G. Beale ${ }^{2,}$, Nasim Khalil Shatarat ${ }^{1}$ and Mutasem A. Shehadeh ${ }^{3}$ \\ ${ }^{1}$ Professor, Department of Civil Engineering, School of Engineering, The University of Jordan, Amman, Jordan \\ ${ }^{2}$ Visiting Research Fellow, Faculty of Design, Technology and Environment, Oxford Brookes University, Wheatley, Oxford, UK \\ ${ }^{3}$ Associate Professor, Department of Mechanical Engineering, American University of Beirut, Beirut, Lebanon \\ "(Corresponding author: E-mail rgbeale@brookes.ac.uk)
}

\section{A B S T RA C T}

Cyclic load tests were conducted on the spigot connections for a system scaffold. Two different connections were tested, one where both ends of a spigot were bolted to tubes and the other where one end was bolted and the other end welded. The tests were conducted by applying a series of different fixed axial loads together with a variable side load which was increased until failure occurred. The objective of undertaking cyclic tests was to not only obtain the rotational stiffness of the connection but also the looseness in the connection as looseness has been shown to reduce the performance of frames, and previous research and experiments involving spigots have ignored these effects.

The tests and accompanying finite element calculations showed that the looseness was 0.009 radians for the double bolted spigot and 0.005 radians for the welded connection. The connections proved to be relatively unstable at high axial loads showing considerable scatter in the results. The results were in agreement with the stiffness results obtained by André that for a range of axial loads a single rotational stiffness could be applied but that for low and high axial loads different stiffnesses must be used.

\section{A R T I C L E H I S T O R Y}

$\begin{array}{ll}\text { Received: } & \text { 30 June } 2017 \\ \text { Revised: } & \text { 18 November } 2017 \\ \text { Accepted: } & \text { 11 January } 2018\end{array}$

\section{K E Y W O R D S}

Cyclic loading

Spigots;

Tubular scaffolds;

Failure

Copyright $\odot 2019$ by The Hong Kong Institute of Steel Construction. All rights reserved.

\section{Introduction}

Following a series of bridge falsework and scaffold failures in the early 1970s the UK government commissioned the Bragg Report [1] which ultimately led to the development of BS 5975 [2]. It was known that the traditional UK procedures of analysing temporary works structures by only considering the effective lengths of the columns did not allow for the interaction between horizontal beams and the columns which could precipitate failure. Therefore, the UK Science Research Council funded Lightfoot and co-workers [3, 4] to develop a theoretical model of scaffold structures. They used a finite element program where the beam and column elements were modelled using stability functions. Due to the limited capacity of computers in the early 1970s all the joints were modelled as either pinned or fixed connections and joint and member eccentricity was excluded. The models also analysed simple tower structures with only one or two lifts. Experimental scaled models were constructed and tested. Both the experimental and theoretical models failed by buckling with the theoretical buckling loads being between $10 \%$ and $15 \%$ higher than the experimental values. Lightfoot and his co-workers accounted for the difference between their analytical and experimental models by the use of rigid connections and the noninclusion of eccentricities.

Since that time research into scaffold and temporary works structures has been extensive. The emphasis of the research has been into the structural analysis of the components- the beams, columns and connections. The research has been summarised by Beale in a review paper [5] and in a book (with André) [6]. The tubular sections are usually made of steel or aluminium, except in Asia and Central America where bamboo is sometimes used [6]. In the UK the vertical members are called standards and the horizontal beams are called ledgers and transoms for access scaffold structures. There are two principle types of scaffold structure, namely tube and fitting scaffolds (UK name) and system or proprietary scaffolds (which includes modular scaffolds). In the case of tubular scaffolds connections are made by using external components called couplers such as 'right-angled couplers' or 'putlog couplers'. In system or proprietary scaffolds the tubes have a part of the spigot connection welded to one end of the tube and the horizontal members are attached with additional tongues or wedges welded to their ends so that connections can be easily made. As the connections are not rigid but have different rotational stiffnesses about each axis tests must be made to determine these stiffnesses. A common test is simply to fix a section of the standard to an external rig and attach a small section of the horizontal member by the connection in a cantilever and then apply a load to the end of the cantilever. This applies a moment to the joint and by increasing the applied load the momentrotation curve can be determined. The European codes BS EN 12811 [7] and BS EN 74-1 [8] require the load to be cycled through zero to get both the positive and negative rotational characteristics of the connection as well as obtaining an estimate of the looseness of the connection. Note that the use of BS in European code references is to show that the standard is the English Language version. Unfortunately, many analyses and tests conducted on scaffolds increase the loads monotonically to failure and do not consider looseness or the differences in rotational stiffness or capacity for rotations if alternative directions which could occur under wind-load conditions. All connections contain looseness. For example, Abdel-Jaber et al [9] determined the rotation capacity of tube and fitting scaffold connections determining looseness in all of them. Prabhakaran et al [10] showed that for unbraced scaffolds a small rotational looseness of 0.01 rad makes a significant difference to the structural behaviour but that for braced scaffolds the effects are smaller This was particularly important when the effect of erecting standards out-of-plumb was considered. Prabhakaran also showed that the traditional assumption in design that a small out-of-plumb (less than $2 \%$ ) could be modelled by applying a side load of the same order gave different answers for unbraced frames. In the case of the frame analysed by Prabhakaran the looseness reduced the capacity of single bay scaffold frame by $8 \%$. Recent papers by Cimellaro and Domaneschi [11], Sevim et al [12], Peng et al [13,14] and Liu et al [15] investigate the capacity of both system and tubular scaffolds by loading their trial scaffolds monotonically to failure and ignore looseness or any cyclic loading. In addition, a common mistake that is made is to assume that linear buckling analyses ignore the self-weight of the scaffold and only increase the live load at the top of the scaffold. This assumption is valid for scaffolds with only a few lifts or levels but in multi-storey scaffolds the dead load can often be over $50 \%$ of the total load applied to the structure and alternative procedures must be adopted to obtain correct buckling patterns [18, 19].

The columns, which are called standards in the UK for a large scaffold or falsework structure, are made of multiple vertical elements connected together by spigots or couplers. Lightfoot assumed that the coupler could be considered a rigid connection. This assumption is still used for traditional tube-and-fitting scaffolds joined by external sleeved couplers or by parallel couplers (A parallel coupler places the two standards side by side with an offset). Tests on these connections in the European codes (BS EN 12811 and BS EN 74-1) are simple pull-out tests to obtain the ultimate tensile failure load of the connection (for parallel couplers only) or the slipping load (for both sleeved and parallel couplers) $[7,8]$. For sleeved couplers four-point bending tests are conducted as shown in Fig. 1 to get the moment-rotation curves. In Fig. 1, P is the applied side load and $\mathrm{L}$ the length of the specimen with a maximum length of $500 \mathrm{~mm}$ Commonly the looseness found in couplers is ignored for these connections. An assumption is also made for these couplers that the axial force acting on the coupler has no effect on the moment-rotation characteristic curve of the connection. 


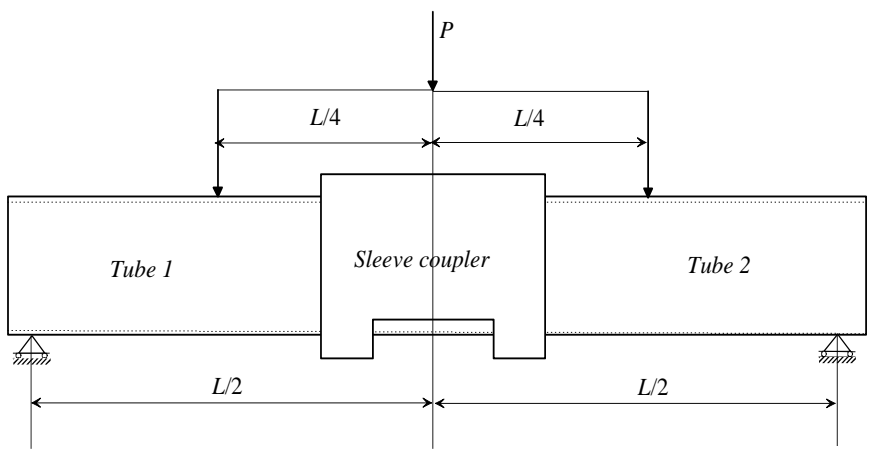

Fig. 1. Schematic of a four-point bending test for sleeved connections.

In proprietary and modular scaffolds the end of one tube has a spigot welded or bolted into the inside of the tube. The second tube is then bolted onto the spigot connection. In these cases, the spigot has a smaller outside diameter than the internal diameter of the standards. According to the European code BS EN 74-1 [8] the total length of the spigot should be equal to or greater than $300 \mathrm{~mm}$. The spigot can be connected to the upper (and lower) standard(s) by pins, by bolts inserted through centred holes or by locking the upper standard to a special connector welded to the spigot wall. See Fig. 2 for a schematic of two tubes joined by a welded spigot and a photograph of the spigot connection analysed in this research. Note the looseness within the connection which cannot be removed.

A prototype proprietary scaffold $\left(\right.$ Cuplock $\left.^{\circledR}\right)$ consisting of three bays and three sets of horizontal members, was tested at Stuttgart during the development of BS EN 12811 [7]. The prototype structure was analysed by Beale and Godley [18]. They showed that 2-D and 3-D nonlinear analyses ignoring spigot looseness give results where the maximum deflection was only half that observed in the tests, although the failure loads were predicted accurately. Only when contact elements at spigot joints were added to the analysis, allowing for the rotation within the connection of 0.1 radians before a rigid contact was assumed, was a good correlation between theory and experiment obtained. Note that the use of 0.1 radians is high but the Cuplock ${ }^{\circledR}$ scaffold used had a slightly conical shape which meant that its looseness was greater than those reported in the tests in this paper. The maximum loads in all the analyses were approximately the same as there were no appreciable side loads. See Fig. 3. Prabhakaran [10] shows the effects of a small rotational looseness on scaffold frames, particularly when side loads, such as wind or effects of standards out-of-plumb are taken into account.

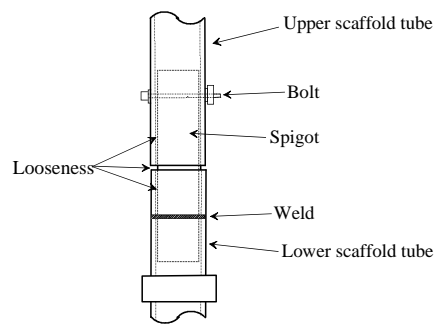

(a) Schematic of two scaffold tubes connected by a spigot

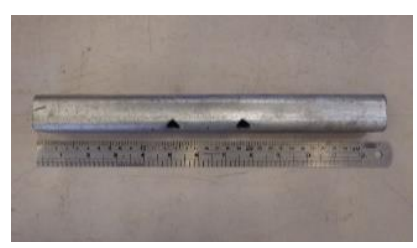

(b) photograph of spigot
Fig. 2. Spigot arrangement

In racking structures, it is well known that the moment-rotation characteristic curve for a baseplate to column connection not only depends upon the applied moment to the connection but also upon the axial force being transmitted through the column to the baseplate and tests have been conducted to develop curves for different applied moments [19, 20]. Similar results relating moment-rotation stiffness to axial force were found in tests on components of proprietary scaffolds containing spigots [21-24].

A detailed study of the Cuplok $^{\circledR}$ proprietary fasework was undertaken at thr University of Sydney, Australia, starting with an investigation of the spigot joint by Enright et al [25] using tests and nonlinear computer models. The Sydney research team then tested the individual components to determine connection and material properties followed by tests on falsework assemblies $[23,24]$.

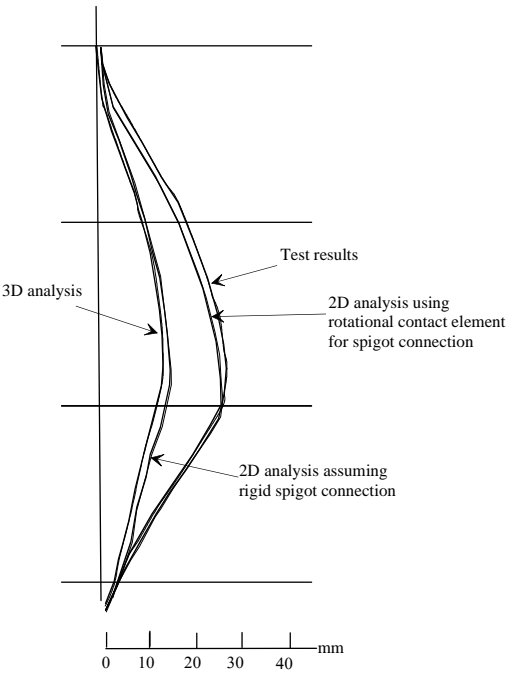

Fig. 3. Comparison between the deflection of the prototype scaffold structure calculated using different analysis models

In the Enright model [25], the spigot is considered to be rigid (300 $\mathrm{mm}$ long) and is connected to the top and bottom standards by short elements with high rigidity $(E I)$ and high axial stiffness $(E A)$ which can only transfer lateral force into the spigot. The vertical load is transferred directly from the top standard to the bottom standard. See Fig. 4. The pinned connections between the standards and the spigot ensure that no vertical forces are applied to the spigot and only lateral forces are transferred via the spigot which cause the standards to bend, the amount of bending depending upon the amount of out-of-plumb of the standards and the value of the load being transmitted from the top to the bottom standard. This model does not model the contact problem between the standard and spigot. Eccentricity at the connection due to lateral displacement had to be included explicitly and was a fixed size for a given analysis and therefore could not be used for models where the rotation changed as the scaffold was loaded. The model was found by André [21] not to give consistent results.

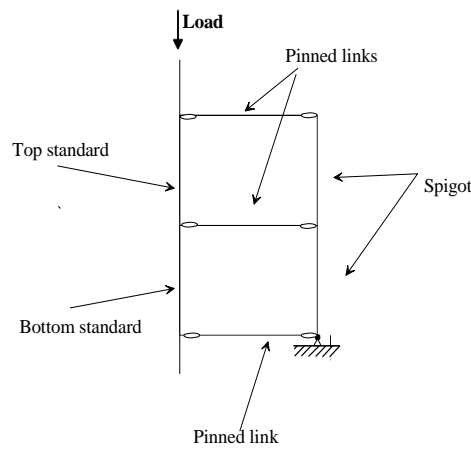

Fig. 4. Schematic of Enright's model [25]

André conducted experiments on both new and used Cuplok ${ }^{\circledR}$ spigot connections testing them in the normal manner reserved for baseplates [21, 22]. This method was also adopted for the tests conducted in this paper and is described in more detail below. André found little difference between the stiffnesses of new and used connections but his results could be due to the fact the specimens were donated by Harsco who manufactured them and only donated new and slightly used connections. In processing his results André used the same multilinear model of moment-curvature presented by Chandrangsu et al [23, 24] and shown in Fig. 5. Note that this 4-step model was created by Chandrangsu to enable an accurate numerical modelling of full-scale scaffolds undertaken in Sydney. For many analyses only one or two rotational stiffnesses are required. Note that the rotational stiffnesses in clockwise and anti-rotations of a connection are usually different, especially for system scaffolds but also for some tube and fitting scaffold connections. BS EN 12811-3 [26] states that the average could be used if the differences in stiffness between the two directions is less than $10 \%$.

Fig. 5 clearly demonstrates the looseness that occur within the section. André was unable to develop a theoretical model for the spigot connection but for each of the 4 stiffness values he produced a statistical model enabling the stiffness to be found for a given axial load. The statistical model showed that the rotationa stiffnesses were dependent upon the axial load in the connection but that this could be approximated by three regions defined by the ratio of axial load $(\mathrm{kN})$ divided by divided by the applied transverse moment (i.e. kN/M). The regions are- stiffnesses (a) below $20 \mathrm{~N} / \mathrm{M}$; (b) between $20-50 \mathrm{~N} / \mathrm{M}$; and (c) above 50 
N/M.).

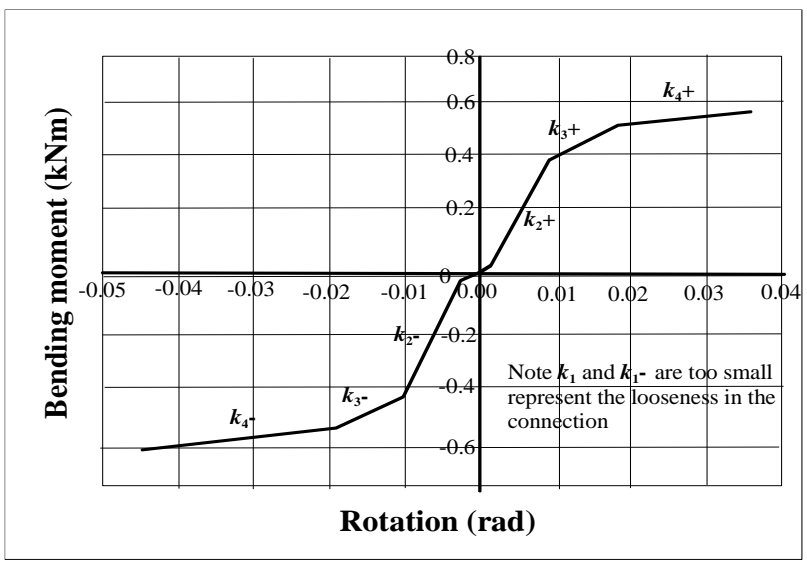

Fig. 5. Approximation of the $M-\theta$ curves (André, [19])

An example is given in Fig. 6. This statistical model enabled the analyses conducted by André to be more accurate than those undertaken by Chandrangsu $[10,24]$. It is not normally necessary to determine four rotational stiffnesses for design analyses. The European code BS EN 12811-3:2002 [26] only requires a tri-linear curve with two initial stiffnesses, one from zero up to the design working load followed by the stiffness between the design working load and the design maximum load. The third line is simply the design maximum load until failure. Prabhakaran [10, 27] showed that the bi-linear model in the storage rack code BS EN 15512 [20] gave the same results and is probably more useful in design as it easier to apply.

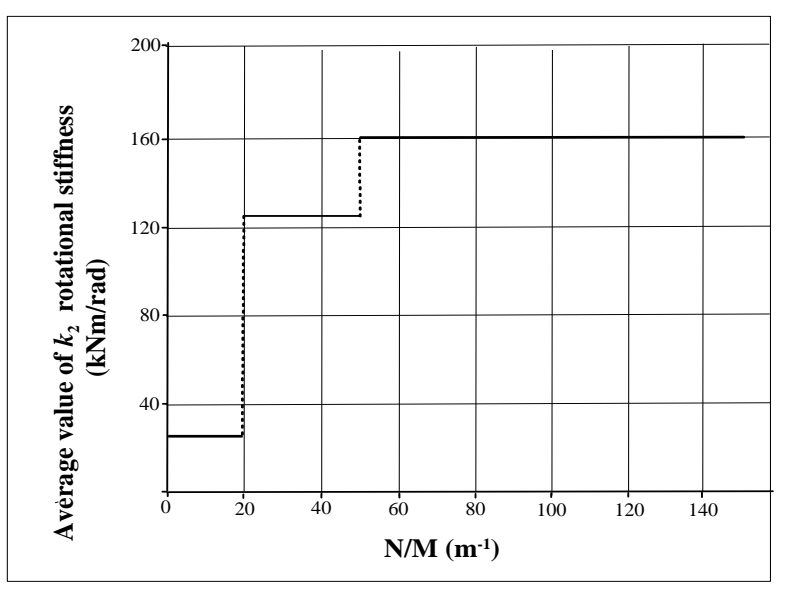

Fig. 6. $k_{2}$ stiffness as a function of $N / M$ ratio (André, [19])

However, the objective of this paper is conduct finite element detailed calculations of the connection and verify them against experimental tests of the connection behaviour.

\section{Experimental procedure}

\subsection{Introduction}

The experimental configuration to determine the rotation stiffness of spigot connections is identical to that of the baseplate test defined in the European standard for baseplates of racking structures [20] with the exception that there is no need for a block of concrete or other material between two sections of standard. In each test a fixed axial load was first applied to the standards and then the side load was applied incrementally to the connection. A schematic of the test is shown in Fig. 7. An example of a spigot under test undertaken by is shown in Fig. 8.

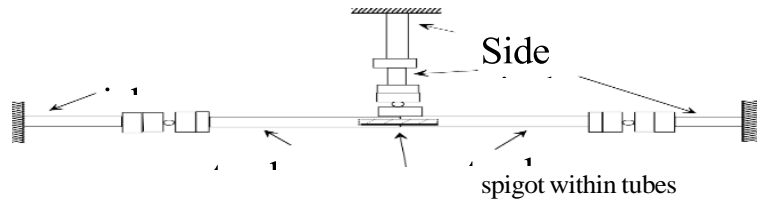

Fig. 7. Schematic of the test procedure for spigots

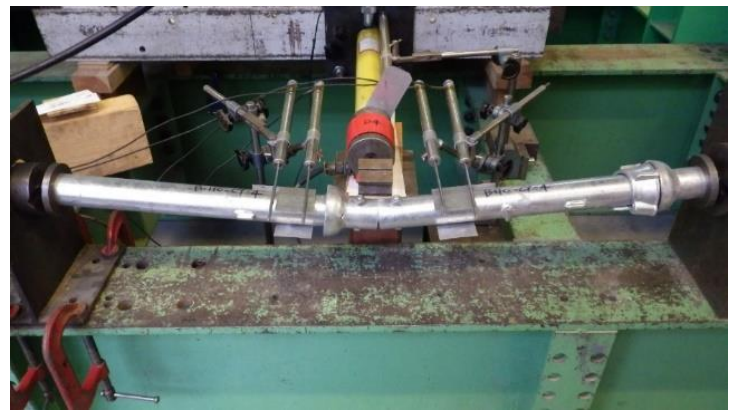

Fig. 8. Spigot under test

In order to get an estimate of the maximum capacity of a connection under a fixed side load a pilot test was undertaken for each axial load loading to failure. Previous researchers had not determined the looseness of spigot connections. Therefore at least three tests were undertaken with the side load cycled between $60 \%$ of the pilot load failure and zero. The side load jack was unable to apply tensile loads to the specimen as this would have meant applying a collar around the connection which would have prevented the spigot deforming (as seen in Fig. 8) and so the normal BS EN 12811- 3 [26] procedure of cycling through zero and including tensile as well as compressive side loads was unable to be undertaken. However, as spigot connections are symmetric the tensile and negative loosenesses were likely to be similar it was considered that cycling between zero transverse load to $60 \%$ of the maximum pilot transverse load would give a reasonable estimate of looseness. Note that it is impossible to determine looseness in monotonic tests as hysteresis loops do not return to zero rotation when the side load is unloaded to zero. From Figs. 11 and 12 below it can clearly be seen that the initial loading path is different to reloading paths which tend to be close together. The looseness is derived from the difference between zero and linearly extrapolating the third reloading curve to obtain the rotation at zero axial load. Ideally, if it was possible to fully cycle between positive and negative rotations the looseness would be taken as half the difference between the positive looseness and the negative looseness. Looseness must be determined as all real structures are subject to dynamic loads, particularly wind but occasionally earthquake. Blackmore [28] recorded several incidences where wind load caused scaffold systems to collapse and Beale and Godley [17] showed that lateral wind loads for Northern Scotland could be of the order of $50 \%$ of the total vertical imposed and dead loads on a scaffold structure and used these results when producing and validating the load tables for the National Access Scaffold Confederation in NASC TG20:13 [29].

A series of tests was undertaken with different axial loads with the two types of spigot connection to see if there was any difference in performance. The two types of spigot connection were: (i) the spigot welded to one standard and bolted to the other, called a welded spigot connection in the remainder of the paper and (ii) the spigot bolted to both standards, called a bolted spigot connection for the remainder of the paper.

From Fig. 8 it can be seen that 4 LVDTs (Linear variable differential transducers) were used to measure the rotation of the standard. The rotation at time step $t, \theta_{t}$, is given by Eq. 1 :

$\theta_{t}=\frac{d_{t, 2}-d_{t, 1}}{L_{D}}+\frac{d_{t, 3}-d_{t, 4}}{L_{D}}$

where $d_{i, 1}, d_{i, 2}, d_{i, 3}, d_{i, 4}$ are the displacements of transducers 1 to 4 at load increment $i$ as shown in Fig. 9 and $L_{d}$ is the spacing between the transducers on each side. Note that they were placed close to the spigot connection so that bending rotation in the standards was neglected. In the tests each section of standards was $490 \mathrm{~mm}$ long and the transducers were placed $50 \mathrm{~mm}$ apart. The transducer locations are clearly visible in the photograph, Fig. 8 above.

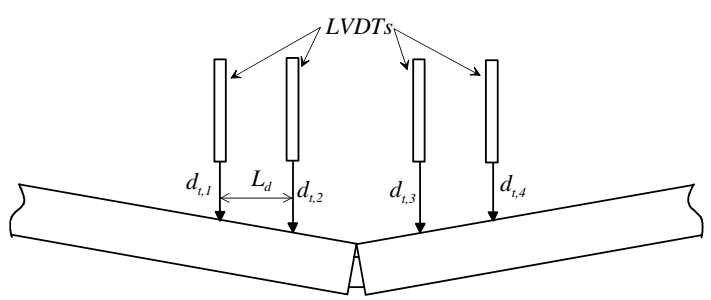

Fig. 9. Schematic showing LVDT nomenclature

Examples of the common failures are shown in Fig. 10. 

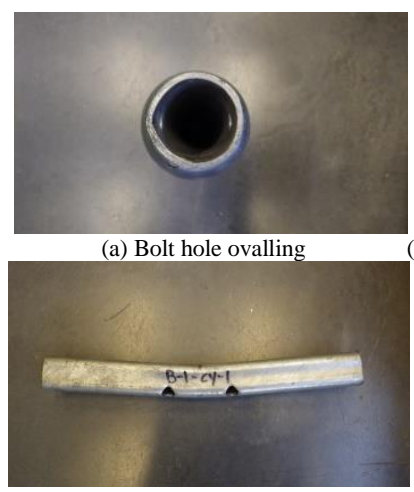

(c) Plastic deformation of bolted spigot
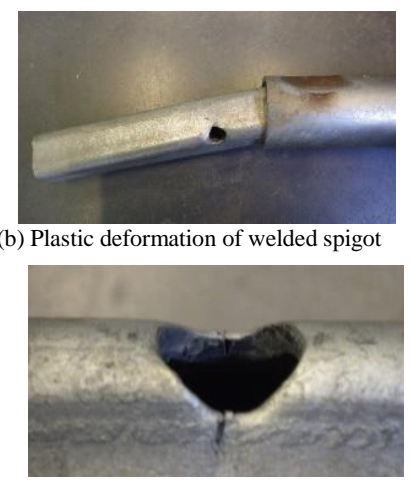

(d) Crack adjacent to bolt hole

Fig. 10. Examples of failed specimens

The material properties of the samples were determined by tensile tests on tubes and spigots and by Vickers Hardness tests on the bolts and welds. It is notable that several recent papers imply that the only material testing required is the material of the tube and do not test the connection material, for example the paper by Lie et al [15]. The material used for the tubes and spigots was according to the Chinese specification for high strength low alloy structural steel GB/T/1591-2008 [30]. Material results are presented in Table 1. It is notable that the material used in the bolts and welding had higher ultimate yield stresses than the material used for the tubes and spigots. Hence all failures occurred with either distortion of the tube or plastic failure of the spigot.

Table 1

Material properties of the test components

\begin{tabular}{lclll}
\hline \multicolumn{1}{c}{ Component } & $\begin{array}{c}\text { Modulus } \\
\text { of } \\
\text { Elasticity } \\
\text { (GPa) }\end{array}$ & $\begin{array}{c}\mathbf{2 \%} \text { Yield } \\
\text { Strength } \\
(\text { YS) }(\text { MPa) }\end{array}$ & $\begin{array}{c}\text { Ultimate } \\
\text { Yield } \\
\text { Strength } \\
\text { (UTS) } \\
\text { (MPa) }\end{array}$ & $\begin{array}{c}\text { Test } \\
\text { procedure }\end{array}$ \\
\hline scaffold tubes & 206 & 385 & 457 & tensile test \\
spigots & 211 & 442 & 535 & tensile test \\
weld & & & 649 & hardness test \\
bolt & & 867 & hardness test \\
\hline
\end{tabular}

\subsection{Experimental results}

Pilot tests on spigot connections were undertaken without any side load and by simply applying an axial load. The resulting failure loads were $142 \mathrm{kN}$ for the double bolted spigot connection and $152 \mathrm{kN}$ for the welded spigot connection. Hence the original design was to conduct tests on the connections with axial loads up to $120 \mathrm{kN}$.

The moment-rotation curves for the cyclic tests are given in Figs. 11 and 12.

Table 2 shows the results of the experiments. The code used in the results are: test number - as performed - but rearranged in the table in order to make the results easier to analyse and understand. The letter $\mathrm{B}$ or $\mathrm{W}$ at the beginning of the test name was to distinguish between spigots have one end welded and the other bolted $(\mathrm{W})$ from those where both ends were bolted (B). The letter P refers to pilot tests with no transverse load. The letters $\mathrm{CY}$ referred to cyclic tests which were performed on specimens before the same specimens were tested to failure where a letter $\mathrm{L}$ was then appended. From the test results shown in Table 2 it can be seen that the cyclic behaviour was only reliable for axial loads up to $90 \mathrm{kN}$. Tests were conducted at axial loads of $110 \mathrm{kN}$ for bolted spigots and $120 \mathrm{kN}$ for both bolted and welded spigots. However, in many cases, as recorded in Table 2 the tests had large scatter and the results were unreliable. Examples of the scatter are shown in W-120-CY tests shown Fig. 12.

The looseness in each test was determined by plotting a regression straight line from the lowest part of the third loading cycle and determining its intercept with the $\mathrm{x}$ axis. The regression line was only accepted if its correlation coefficient, $r^{2}$, was greater than 0.95 . See Fig. 13 .

From the test results shown in Table 2 it can be seen that the cyclic behaviour was only reliable for axial loads up to $90 \mathrm{kN}$. Tests were conducted at axial loads of $110 \mathrm{kN}$ for bolted spigots and $120 \mathrm{kN}$ for both bolted and welded spigots. However, in many cases, as recorded in Table 2 the tests had large scatter and the results were unreliable. Examples of the scatter are shown in W-120-CY tests shown Fig. 12.

The looseness in each test was determined by plotting a regression straight line from the lowest part of the third loading cycle and determining its intercept with the $\mathrm{x}$ axis. The regression line was only accepted if its correlation coefficient, $r^{2}$, was greater than 0.95 . See Fig. 13 .
Table 2

Summary of experimental results

\begin{tabular}{|c|c|c|c|c|}
\hline $\begin{array}{l}\text { Test } \\
\text { No. }\end{array}$ & Name & $\begin{array}{l}\text { Max } \\
\text { side } \\
\text { load } \\
(\mathbf{k N}) \\
\end{array}$ & Description & $\begin{array}{l}\text { Loosenes } \\
\mathrm{s}\end{array}$ \\
\hline 1 & B-C1 & & $\begin{array}{l}\text { Pilot test, axial load only; } \\
\text { failed at } 142 \mathrm{kN}\end{array}$ & \\
\hline 2 & B-P-B1 & 5.84 & $\begin{array}{l}\text { Pilot test, side load only, spigot } \\
\text { failed with side load } 5.84 \mathrm{kN}\end{array}$ & \\
\hline 3 & W1-BP & & $\begin{array}{l}\text { Pilot test, immediate failure } \\
\text { with tube slipping, slight tube } \\
\text { ovalling }\end{array}$ & \\
\hline $3 R$ & WC-1P & & $\begin{array}{l}\text { Pilot test, no side load, failed } \\
152 \mathrm{kN}\end{array}$ & \\
\hline 4 & B-30-LF & 4.614 & $\begin{array}{l}\text { Pilot test, large deflection, } \\
\text { spigot failure }\end{array}$ & \\
\hline 5 & B-60-LF & 3.794 & Pilot test, tubes ovalled & \\
\hline 6 & B-90-LF & 3.699 & Pilot test, tubes ovalled slightly & \\
\hline 7 & B-120-LF & 3.775 & $\begin{array}{l}\text { Pilot test, small tube ovalling, } \\
\text { spigot bent }\end{array}$ & \\
\hline 8 & B-140-LF & & $\begin{array}{l}\text { Pilot test, test failed under } 135 \\
\text { kN axial load, no side load }\end{array}$ & \\
\hline 9 & WB-30-LF & 4.957 & $\begin{array}{l}\text { Pilot test, slight ovalling, small } \\
\text { tearing at bolt hole }\end{array}$ & \\
\hline 10 & WB-60-LF & 4.245 & $\begin{array}{l}\text { Pilot test, slight ovalling, small } \\
\text { tearing at bolt hole, spigot bent }\end{array}$ & \\
\hline 11 & WB-90-LF & 3.606 & $\begin{array}{l}\text { Pilot test, bolted tube went } \\
\text { under welded tube }\end{array}$ & \\
\hline 12 & WB-120-LF & 1.529 & Pilot test, early failure & \\
\hline 13 & WB-140-LF & & $\begin{array}{l}\text { Pilot test, failed at } 137 \mathrm{kN} \text {, no } \\
\text { side load }\end{array}$ & \\
\hline 26 & W-1-CY-1 & 3.33 & Test successful & 0.0008 \\
\hline $26 \mathrm{~L}$ & W-1-CY-1L & 5.20 & $\begin{array}{l}\text { Spigot bent, tube ovalling, bolt } \\
\text { thread cutting into bolt hole }\end{array}$ & \\
\hline 27 & W-1-CY-2 & 3.32 & Test successful & 0.0180 \\
\hline $27 \mathrm{~L}$ & W-1-CY-2L & 5.37 & $\begin{array}{l}\text { Spigot bent, tube ovalling, load } \\
\text { dropped during test with no } \\
\text { reason apparent, specimen then } \\
\text { fell out of rig }\end{array}$ & \\
\hline 28 & W-1-CY-3 & 3.33 & Test successful & 0.0058 \\
\hline $28 \mathrm{~L}$ & W-1-CY-3L & 5.28 & No description recorded & \\
\hline 52 & $\mathrm{~W}-1-\mathrm{CY}-4$ & 3.33 & $\begin{array}{l}\text { Test successful, large scatter in } \\
\text { data points }\end{array}$ & 0.0055 \\
\hline $52 \mathrm{~L}$ & W-1-CY-4L & 5.18 & $\begin{array}{l}\text { Spigot bent, ovalling of non- } \\
\text { welded tube }\end{array}$ & \\
\hline 14 & W-30-CY-1 & 2.88 & Test successful & 0.0021 \\
\hline $14 \mathrm{~L}$ & W-30-CY-1L & 5.01 & Spigot bent, tube ovallling & \\
\hline 15 & W-30-CY-2 & 2.87 & Test successful & 0.0027 \\
\hline $15 \mathrm{~L}$ & W-30-CY-2L & 5.36 & Spigot bent, tube ovalling & \\
\hline 16 & W-30-CY-3 & 2.88 & Test successful & 0.0033 \\
\hline $16 \mathrm{~L}$ & W-30-CY-3L & 4.50 & $\begin{array}{l}\text { Spigot bent, slight elongation } \\
\text { and ovalling of the tube }\end{array}$ & \\
\hline 50 & W-30-CY-4 & 2.87 & $\begin{array}{l}\text { Test successful, large scatter in } \\
\text { data but terminating at same } \\
\text { looseness }\end{array}$ & 0.0096 \\
\hline $50 \mathrm{~L}$ & W-30-CY-4L & 4.63 & $\begin{array}{l}\text { Spigot bent, ovalling of non- } \\
\text { welded tube }\end{array}$ & \\
\hline 17 & W-60-CY-1 & 2.47 & $\begin{array}{l}\text { Test successful, slight on } \\
\text { rotation measurements }\end{array}$ & 0.0009 \\
\hline $17 \mathrm{~L}$ & W-60-CY-1L & 3.91 & $\begin{array}{l}\text { Spigot bent, small ovalling of } \\
\text { tubes }\end{array}$ & \\
\hline 18 & W-60-CY-2 & 2.48 & Test successful & -0.0002 \\
\hline $18 \mathrm{~L}$ & W-60-CY-2L & 4.12 & $\begin{array}{l}\text { Spigot bent, small ovalling of } \\
\text { tubes }\end{array}$ & \\
\hline 19 & W-60-CY-3 & 2.47 & $\begin{array}{l}\text { Test successful, large scatter in } \\
\text { measurements, slight drift } \\
\text { between cycles }\end{array}$ & 0.0019 \\
\hline 19L & W-60-CY-3L & 3.89 & $\begin{array}{l}\text { Spigot bent, small ovalling of } \\
\text { tubes }\end{array}$ & \\
\hline 51 & W-60-CY-4 & 2.46 & $\begin{array}{l}\text { Unable to determine looseness } \\
\text { as too much scatter between } \\
\text { cycles, possible instrument } \\
\text { fault }\end{array}$ & \\
\hline $51 \mathrm{~L}$ & W-60-CY-1L & & $\begin{array}{l}\text { Spigot bent, ovalling of non- } \\
\text { welded tube }\end{array}$ & \\
\hline 20 & W-90-CY-1 & 2.04 & $\begin{array}{l}\text { Test successful but sample } \\
\text { close to failure,increasing } \\
\text { deflection between cycles and } \\
\text { large hysteresis }\end{array}$ & 0.0192 \\
\hline $20 \mathrm{~L}$ & W-90-CY-1L & 6.64 & Lower than cyclic & \\
\hline
\end{tabular}




\begin{tabular}{|c|c|c|c|c|c|c|c|c|c|}
\hline $\begin{array}{l}\text { Test } \\
\text { No. }\end{array}$ & Name & $\begin{array}{l}\text { Max } \\
\text { side } \\
\text { load } \\
(\mathbf{k N}) \\
\end{array}$ & Description & $\begin{array}{l}\text { Loosenes } \\
\text { s }\end{array}$ & $\begin{array}{l}\text { Test } \\
\text { No. }\end{array}$ & Name & $\begin{array}{l}\text { Max } \\
\text { side } \\
\text { load } \\
(\mathbf{k N}) \\
\end{array}$ & Description & Looseness \\
\hline 21 & W-90-CY-2 & 2.66 & $\begin{array}{l}\text { Load not cycled, displacements } \\
\text { show problems with } \\
\text { instrumentation, looseness not } \\
\text { determined }\end{array}$ & & $36 \mathrm{~L}$ & B-60-C3-2L & 2.23 & $\begin{array}{l}\text { Spigot bent, elongation and } \\
\text { ovalling of the tubes }\end{array}$ & 0.0004 \\
\hline $21 \mathrm{~L}$ & W-90-CY-2L & 4.24 & $\begin{array}{l}\text { Test failed with downward } \\
\text { displacement; local elongation } \\
\text { of tube in line with bolt, bolt } \\
\text { bent, tearing and crushing }\end{array}$ & & $37 \mathrm{~L}$ & B-60-CY-3L & 3.89 & $\begin{array}{l}\text { Test successful } \\
\text { Spigot bent, elongation and } \\
\text { ovalling of the tubes }\end{array}$ & 0.0020 \\
\hline 22 & W-90-CY-3 & 2.07 & $\begin{array}{l}\text { bent, tearing and crushing } \\
\text { around bolt hole } \\
\text { Test successful }\end{array}$ & 0.0012 & 49 & B-60-CY-4 & 2.23 & $\begin{array}{l}\text { Test successful, plot shows } \\
\text { large scatter in individual } \\
\text { points, looseness result low } r^{2}\end{array}$ & 0.0008 \\
\hline $22 \mathrm{~L}$ & W-90-CY-3L & 5.54 & $\begin{array}{l}\text { Spigot bent, small ovalling of } \\
\text { tubes }\end{array}$ & & $49 \mathrm{~L}$ & B-60-CY-4L & 3.42 & $\begin{array}{l}\text { correlation of } 0.89 \\
\text { Spigot bent, ovalling of tubes }\end{array}$ & \\
\hline 44 & W-90-CY-4 & 2.13 & $\begin{array}{l}\text { Test successful, initial rotation } \\
\text { jump removed }\end{array}$ & -0.0012 & 38 & B-90-CY-1 & 2.13 & Test successful & 0.0020 \\
\hline $44 \mathrm{~L}$ & W-90-CY-4L & 2.00 & $\begin{array}{l}\text { Sample failed downwards, } \\
\text { spigot bent, tearing at bolthole } \\
\text { Test successful }\end{array}$ & -0.0015 & $38 \mathrm{~L}$ & B-90-CY-1L & 6.64 & $\begin{array}{l}\text { Spigot bent, small ovalling of } \\
\text { tubes, note specimen recovered } \\
\text { after removal of side load, test }\end{array}$ & \\
\hline $46 \mathrm{~L}$ & W-90-CY-5L & 5.25 & Spigot bent, ovalling of tubes & & 39 & B-90-CY-2 & 2.12 & $\begin{array}{l}\text { results anomalistic and ignored } \\
\text { Sample lifted when side load }\end{array}$ & 0.0099 \\
\hline $23 \mathrm{~L}$ & W-120-CY-1L & 4.24 & $\begin{array}{l}\text { Test successful in that } 3 \text { cycles } \\
\text { completed, unable to determine } \\
\text { looseness due to wide scatter in } \\
\text { results } \\
\text { Spigot bent, small ovalling of } \\
\text { tubes }\end{array}$ & & $39 \mathrm{~L}$ & B-90-CY-2L & 1.59 & $\begin{array}{l}\text { applied; increasing deflections } \\
\text { on each cycle (approx. } 0.1 \text { per } \\
\text { cycle) } \\
\text { Both tubes ovalling, slight tear } \\
\text { at bolt holes into spigot, bolt } \\
\text { thread cutting into spigot }\end{array}$ & \\
\hline 24 & W-120-CY-2 & 0.73 & $\begin{array}{l}\text { Test successful in that } 3 \text { cycles } \\
\text { completed, unable to determine } \\
\text { looseness due to wide scatter in } \\
\text { results }\end{array}$ & & 40 & B-90-CY-3 & 2.12 & $\begin{array}{l}\text { Sample lifted when side load } \\
\text { applied; increasing deflections } \\
\text { on each cycle (approx. } 0.05 \text { per } \\
\text { cycle) }\end{array}$ & 0.0073 \\
\hline $24 \mathrm{~L}$ & W-120-CY-2L & 4.24 & $\begin{array}{l}\text { Spigot bent, small ovalling of } \\
\text { tubes }\end{array}$ & & $40 \mathrm{~L}$ & B-90-CY-3L & 1.95 & $\begin{array}{l}\text { Both tubes ovalling, slight tear } \\
\text { at bolt holes into spigot, bolt }\end{array}$ & \\
\hline 25 & W-120-CY-3 & 0.73 & $\begin{array}{l}\text { Test successful in that } 3 \text { cycles } \\
\text { completed, unable to determine } \\
\text { looseness due to wide scatter in } \\
\text { results }\end{array}$ & & 45 & B-90-CY-4 & 2.14 & $\begin{array}{l}\text { thread cutting into spigot } \\
\text { Test successful; data scattered, } \\
\text { displacements increased on } \\
\text { each cycle, low } \mathrm{r}^{\mathrm{r}} 0.85\end{array}$ & 0.0115 \\
\hline $25 \mathrm{~L}$ & W-120-CY-3L & 1.98 & $\begin{array}{l}\text { Test failed with upward } \\
\text { displacement; ovalling of tube } \\
\text { spigot bent, tearing around bolt } \\
\text { hole }\end{array}$ & & $45 \mathrm{~L}$ & B-90-CY-4L & 2.00 & $\begin{array}{l}\text { correlation } \\
\text { Spigot bent, ovalling of tubes }\end{array}$ & \\
\hline 29 & B-1-CY-1 & 3.32 & Test successful & 0.0255 & 54 & B-110-CY-2 & & Failed at $92 \mathrm{kN}$ axial load & \\
\hline 29L & B-1-CY-1L & 5.65 & $\begin{array}{l}\text { stopped as displacement } \\
\text { control jack reached limt.; }\end{array}$ & & 55 & B-110-CY-3 & & Failed at $104 \mathrm{kN}$ axial load & \\
\hline 30 & B-1-CY-2 & 3.33 & $\begin{array}{l}\text { spigot bent; elongation and } \\
\text { ovalling of tubes } \\
\text { Test successful }\end{array}$ & 0.0388 & 56 & B-110-CY-4 & 2.13 & $\begin{array}{l}\text { Test successful but deflections } \\
\text { increased with each cycle ( } 0.01 \\
\text { between cycles, } 2 \text { only } \\
\text { completed }\end{array}$ & 0.0072 \\
\hline $30 \mathrm{~L}$ & B-1-CY-2L & 5.11 & $\begin{array}{l}\text { Sample twisted in rig, test } \\
\text { stopped before LVDTs } \\
\text { damaged; spigot bent, } \\
\text { elongation and ovalling of the } \\
\text { tubes }\end{array}$ & & $56 \mathrm{~L}$ & B-110-CY-4L & & $\begin{array}{l}\text { Sample moved sideways when } \\
\text { axial load applied, unable to } \\
\text { reach axial load of } 120 \mathrm{kN} \text {, }\end{array}$ & \\
\hline 31 & B-1-CY-3 & 3.33 & Test completed & 0.0307 & & & & $\begin{array}{l}\text { spigot bent, no cycles } \\
\text { performed }\end{array}$ & \\
\hline $31 \mathrm{~L}$ & B-1-CY-3L & 4.99 & $\begin{array}{l}\text { Sample rotated out, LVDTs } 3 \\
\text { and } 4 \text { became disconnected, } \\
\text { end bearing jumped out of end } \\
\text { socket; spigot bent, elongation }\end{array}$ & & 42 & B-120-CY-2 & & $\begin{array}{l}\text { Failed at an axial load of } 110 \\
\mathrm{kN} \text {, no cycles performed, tear } \\
\text { round both bolt holes, ovalling } \\
\text { of both tubes }\end{array}$ & \\
\hline 47 & B-1-CY-4 & 2.62 & $\begin{array}{l}\text { and ovalling of the tubes } \\
\text { Test successful, displacements } \\
\text { increasing on successive cycles }\end{array}$ & 0.0059 & 43 & B-120-CY-3 & 2.13 & Test successful & 0.0020 \\
\hline $47 \mathrm{~L}$ & B-1-CY-4L & 5.00 & $\begin{array}{l}\text { Increasing on successive cycles } \\
\text { Spigot bent, ovalling of one } \\
\text { tube, crushing on opposite side } \\
\text { Test successful }\end{array}$ & 0.0001 & 43L & B-120-CY-3L & 2.91 & $\begin{array}{l}\text { Spigot slightly bent, small } \\
\text { ovalling of tubes, note } \\
\text { specimen recovered after } \\
\text { removal of side load }\end{array}$ & \\
\hline $32 \mathrm{~L}$ & B-30-CY-1L & 4.72 & $\begin{array}{l}\text { Elongation and ovalling of the } \\
\text { tubes, spigot bent and torn } \\
\text { around one of the bolt holes, } \\
\text { thread of one bolt cutting into } \\
\text { spigot }\end{array}$ & & $56 \mathrm{~L}$ & B-110-CY-4L & 2.13 & $\begin{array}{l}\text { Test successful but deflections } \\
\text { increased with each cycle }(0.01 \\
\text { between cycles, } 2 \text { only } \\
\text { completed } \\
\text { Test failed below cyclic load }\end{array}$ & 0.0072 \\
\hline 33 & B-30-CY-2 & 2.62 & $\begin{array}{l}\text { Test successful, deflections } \\
\text { slightly increasing on each } \\
\text { cycle }\end{array}$ & 0.0045 & 41 & B-120-CY-1 & & $\begin{array}{l}\text { Sample moved sideways when } \\
\text { axial load applied, unable to } \\
\text { reach axial load of } 120 \mathrm{kN} \text {. }\end{array}$ & \\
\hline $33 \mathrm{~L}$ & B-30-CY-2L & 4.73 & Spigot bent, ovalling of tubes & & & & & & \\
\hline $34 \mathrm{~L}$ & B-30-CY-3L & 4.92 & $\begin{array}{l}\text { Test successful, feflections } \\
\text { slightly increasing on each } \\
\text { cycle } \\
\text { Spig ot bent, ovalling of tubes }\end{array}$ & 0.0017 & 42 & B-120-CY-2 & & $\begin{array}{l}\text { Failed at an axial load of } 110 \\
\mathrm{kN} \text {, no cycles performed, tear } \\
\text { round both bolt holes, ovalling } \\
\text { of both tubes }\end{array}$ & \\
\hline 48 & B-30-CY-4 & 2.62 & Test successful & 0.0008 & 43 & B-120-CY-3 & 2.13 & Test successful & 0.0020 \\
\hline $48 \mathrm{~L}$ & B-30-CY-4L & 4.25 & Spigot bent, ovalling of tubes & & $43 \mathrm{~L}$ & B-120-CY-3L & 2.91 & $\begin{array}{l}\text { Spigot slightly bent, small } \\
\text { ovalling of tubes, note }\end{array}$ & \\
\hline 35 & B-60-CY-1 & 2.24 & Test successful & 0.0008 & & & & $\begin{array}{l}\text { specimen recovered after } \\
\text { removal of side load }\end{array}$ & \\
\hline $35 \mathrm{~L}$ & B-60-CY-1L & 3.91 & $\begin{array}{l}\text { Spigot bent, elongation and } \\
\text { ovalling of the tubes }\end{array}$ & & & & & & \\
\hline
\end{tabular}



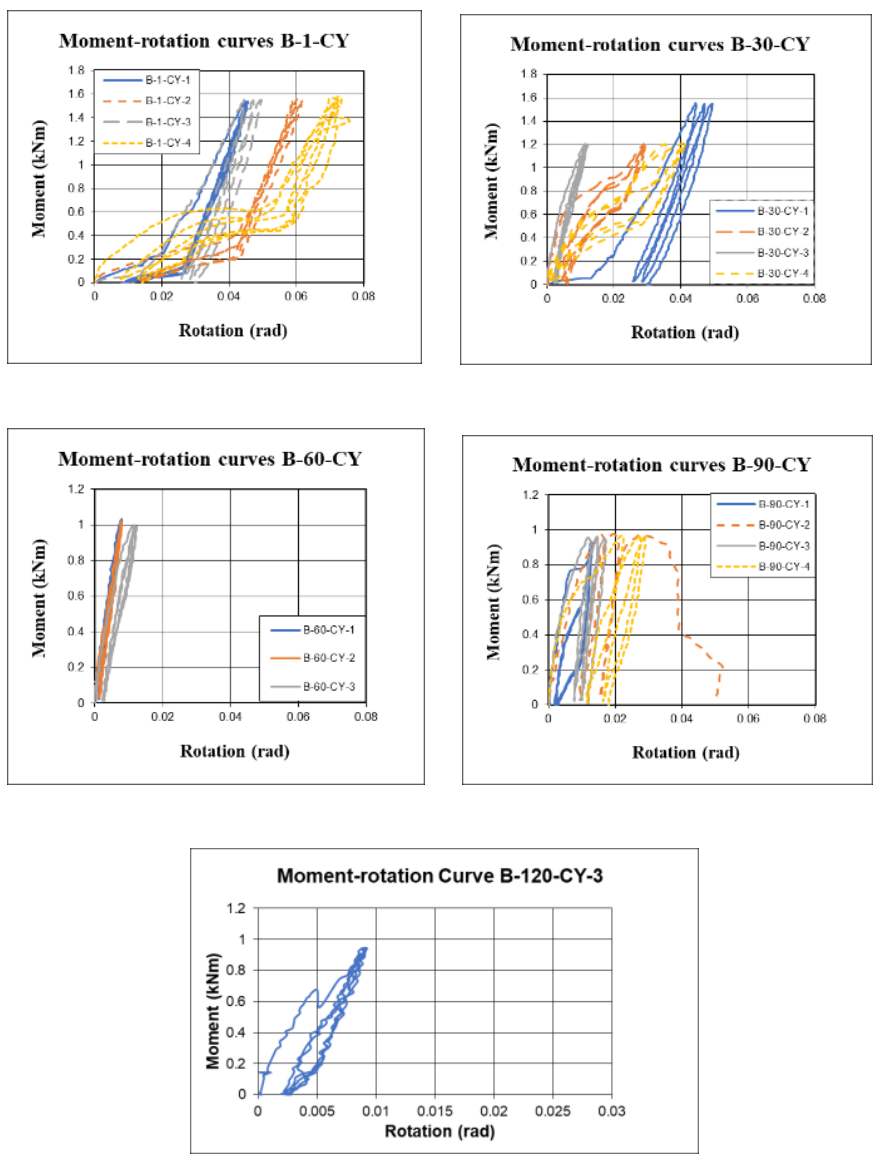

Fig. 11. Moment-rotation curves for the cyclic tests swith bolted spigot
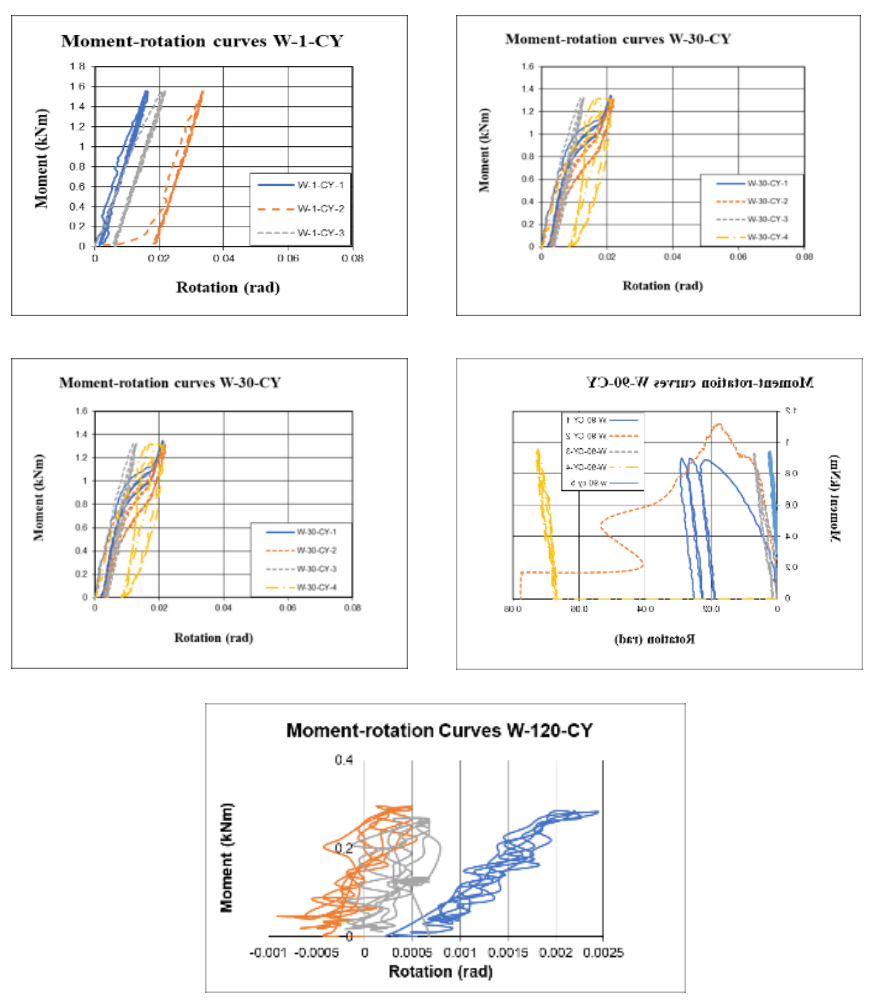

Fig. 12. Moment-rotation curves for the cyclic tests swith welded spigot

Mean and standard deviation values were determined as shown in Table 3. In test B-30-CY-1 a correction to remove initial exceptional looseness was made. The looseness for bolted spigots was greater than that of the welded spigots with an overall mean looseness of 0.0088 radians for the double bolted spigots as opposed to 0.0049 radians for the spigots with one end welded and the other end bolted. The standard deviations were respectively 0.0114 radians for the double bolted spigots and 0.0061 radians for the welded spigots. Note that these values were determined from the original data and not the simplified tables. The size of the looseness in both tests was small but it obvious that all spigots should be welded at one end to reduce the average looseness. The work by Prabhakaran [10] shows that even a small rotational looseness can have deleterious effects on unbraced or poorly braced structures.

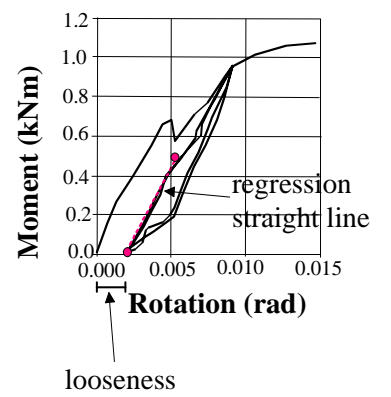

Fig. 13. Determination of looseness

Mean and standard deviation values were determined as shown in Table 3. In test B-30-CY-1 a correction to remove initial exceptional looseness was made. The looseness for bolted spigots was greater than that of the welded spigots with an overall mean looseness of 0.0088 radians for the double bolted spigots as opposed to 0.0049 radians for the spigots with one end welded and the other end bolted. The standard deviations were respectively 0.0114 radians for the double bolted spigots and 0.0061 radians for the welded spigots. Note that these values were determined from the original data and not the simplified tables. The size of the looseness in both tests was small but it obvious that all spigots should be welded at one end to reduce the average looseness. The work by Prabhakaran [10] shows that even a small rotational looseness can have deleterious effects on unbraced or poorly braced structures.

Table 3

Results of looseness calculations under different axial loads

\begin{tabular}{lcccc}
\hline Test group & $\begin{array}{c}\text { Mean } \\
\text { Looseness }\end{array}$ & $\begin{array}{c}\text { Standard } \\
\text { deviation } \\
\text { (rad) }\end{array}$ & $\begin{array}{c}\text { Mean cycle } \\
\text { Maximum } \\
\text { moment }(\mathbf{k N m})\end{array}$ & Comments \\
\hline B-1-CY & 0.0267 & 0.0113 & 1.5481 & \\
B-30-CY & 0.0065 & 0.0085 & 1.2932 & \\
B-60-CY & 0.0012 & 0.0007 & 1.0125 & \\
B-90-CY & 0.0077 & 0.0042 & 0.9566 & No standard \\
B-110-CY & 0.0072 & & 0.9930 & deviation as \\
& & & & only 1 \\
& & & & successful test \\
& & & 0.9428 & No standard \\
deviation as & only 1 \\
B-120-CY & 0.0020 & & & successful test \\
& & & 1.5562 & \\
& & & 1.2932 & \\
W-1-CY & 0.0075 & 0.0074 & 1.0125 & \\
W-30-CY & 0.0044 & 0.0035 & 0.8479 & No looseness \\
W-60-CY & 0.0012 & 0.0007 & 0.2808 & due to large \\
W-90-CY & 0.0058 & 0.0089 & & resulter of \\
W-120-CY & & & & \\
& & & & \\
& & & & \\
\end{tabular}

Once a cyclic test had been completed the connection was then tested to failure by increasing the side load. Fig. 14 shows the moment rotation curves of successful tests. In some cases when the test was conducted with a high axial load the specimen then failed prematurely at loads below the cyclic load as detailed in Table 2. Some of the scatter in the results was attributed to the manufacturing tolerances used to enable users of connections to easily fix one standard on top of a second. This scatter could occur when the standards are connected in full structures and therefore the results must be treated with caution.

The lowest stiffnesses were determined putting a regression linear curve through the first straight part of the curve and the logarithmic mean used to determine the stiffness of the curves. The second stiffness was then determined, again by putting a regression linear curve through the next part until the curvature changed significantly. The results were accepted when the regression curves both had an $r^{2}>0.95$ Table 4 shows the mean maximum moments and the mean stiffnesses with a commentary as to why certain tests were removed.

The results show that, as expected, spigots which are doubly bolted to standards have lower capacity in resisting moments than do standards where the spigots are welded at one end. 
Table 4

Rotational stiffness results and maximum applied side moment

\begin{tabular}{cccccc}
\hline Test group & $\begin{array}{c}\text { Initial } \\
\text { stiffness } \\
(\mathbf{k N m} / \mathbf{r a d})\end{array}$ & $\begin{array}{c}\text { Second } \\
\text { stiffness } \\
(\mathbf{k N m} / \mathbf{r a d})\end{array}$ & $\begin{array}{c}\text { Mean } \\
\text { Maximum } \\
\text { moment } \\
(\mathbf{k N m})\end{array}$ & $\begin{array}{c}\text { Standard } \\
\text { deviation }\end{array}$ & Comments \\
\hline
\end{tabular}

\begin{tabular}{lrccc}
\hline B-1-CY & 9.90 & 106.53 & 2.49 & 0.14 \\
B-30-CY & 112.50 & 33.94 & 2.31 & 0.09 \\
B-60-CY & 113.64 & 160.49 & 1.81 & 0.15 \\
B-90-CY & 153.19 & 107.37 & 0.85 & 0.12 \\
B-110-CY & & & 0.26 & \\
B-120-CY & 127.78 & & 1.37 & \\
& & & & \\
W-1-CY & 130.26 & 107.36 & 2.49 & 0.04 \\
W-30-CY & 136.92 & 51.78 & 2.32 & 0.19 \\
W-60-CY & 132.42 & 51.01 & 2.03 & 0.31 \\
W-90-CY & 96.24 & 69.65 & 1.62 & 0.50 \\
W-120-CY & -133.60 & 74.53 & 2.21 & 0.36 \\
\hline
\end{tabular}

Too much scatter in B-30-CY-3L and B-30-CY-4L to get stiffnesses

Too much scatter in B-60-CY-3L and B-60-CY-4L to get stiffnesses

1 curve only so no standard deviation and too much scatter to get stiffnesses

No standard deviation as only 1 successful test and second stiffness could not be calculated

Too much scatter in W-30-CY-3L and W-30-CY-4L to get stiffnesses

Too much scatter in W-30-CY-3L and W-30-CY-4L to get stiffnesses

Too much scatter to determine second stiffness in W-90-CY-3L

Note that if looseness is properly measured when stiffnesses are determined in accordance with the Eurocode the total looseness is found by adding the initial looseness recorded in Table 3 with the half the difference between the intersects of the regression straight lines of the third loading curve and last cyclic unloading curve with the zero moment axis. These can then be used to obtain a reduced stiffness of the initial slope.
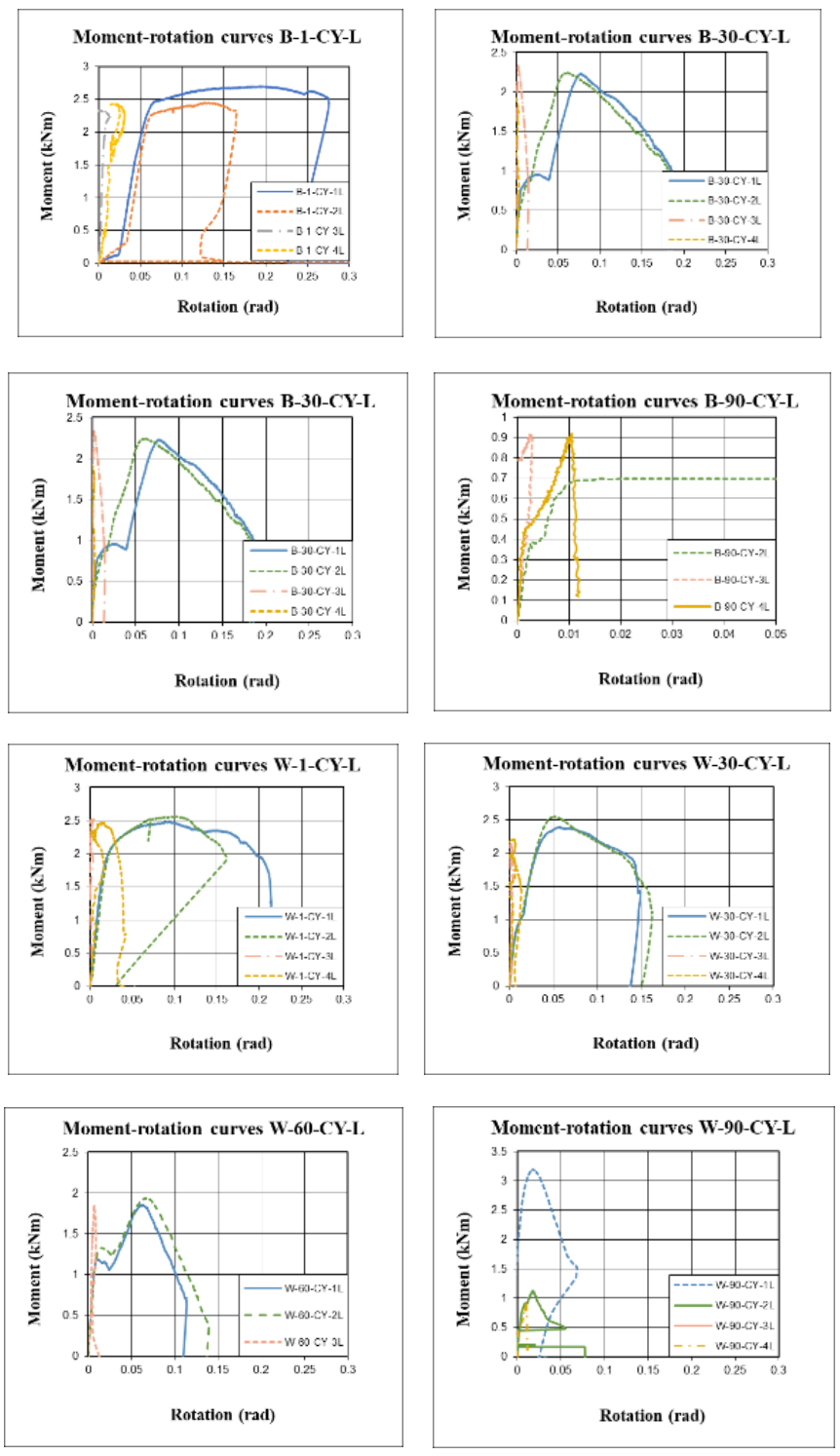

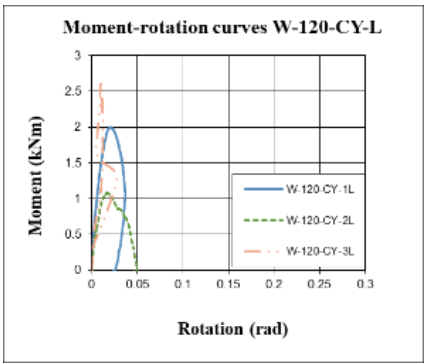

Fig.14 Moment-rotation curves of the connections with different axial loads loaded to failure

The results show that, as expected, spigots which are doubly bolted to standards have lower capacity in resisting moments than do standards where the spigots are welded at one end.

Note that if looseness is properly measured when stiffnesses are determined in accordance with the Eurocode the total looseness is found by adding the initial looseness recorded in Table 3 with the half the difference between the intersects of the regression straight lines of the third loading curve and last cyclic unloading curve with the zero-moment axis. These can then be used to obtain a reduced stiffness of the initial slope.

\section{Finite element analysis}

\subsection{Finite element model}

The system was modelled using SolidWorks and a static structural nonlinear analysis was performed using ANSYS [31]. Five tests were conducted. Each test represented a different axial load level. For each axial load level, the transverse force causing bending was increased until failure of the joint assembly. The finite element model was used to determine the connection stiffness and its maximum capacity.

The two tubes and the spigot were exported from solid works. The three parts were assembled into one system.

Since the objective of the analysis was to determine connection stiffness and its maximum capacity the structural analysis included the elastoplastic region as well as a pure elastic region. Hence the bilinear hardening model in ANSYS was used and the tangent modulus was required.

The bilinear hardening model in ANSYS requires two slopes. One slope is the Young's modulus in the elastic region and the second slope is the plastic tangent modulus. The tangent modulus quantifies the "hardening" of material that generally occurs when it begins to yield.

The tangent modulus was obtained using Eq. 2.

tangent modulus $=\frac{U T S-Y S}{\text { Strain at the UTS }- \text { Strain at the YS }}$

where the UTS is the Ultimate Tensile Strength and the YS is the yield strength.

In the finite element model the automatic procedure in ANSYS generated a constant strain tetrahedral mesh. A simulation using coarse and fine mesh sizes were undertaken. Changing the mesh type to hex dominant failed because the system was loaded dynamically. Hex dominant mesh types in ANSYS are applicable for bodies that do not sweep [16].

Therefore, a mesh sensitivity was done by decreasing the minimum edge 
length until a convergence of the von Mises stress of 3\% was reached in all the elements. The minimum edge length was $4 \mathrm{~mm}$ in all simulations. The final mesh had 16203 elements and is shown in Figs. 15 and 16. Unfortunately, the separation between the two tubes of $1 \mathrm{~mm}$ is not shown in the Figs. of meshes.

Two options were studied concerning the connection between the spigot and the tubes. Option one studied the case where the spigot was bolted to the tube at one end and bolted at the other end and option two studied the case where the upper surface of the spigot was welded to the inner surface of the tube on one end. The following boundary conditions were applied:

- At the right side of the tube where the axial compression was applied, a roller Boundary Condition is applied.

- At the left side of the tube where the axial compression is applied, a pinned boundary condition was used.

Contact properties

- Tube and tube: Frictionless since they are both connected through the spigot

- Bolted option: Bolts are in contact with the pipe and spigot. See Fig. 16.

- Welded option: The outer surface of the spigot is fully bonded to the inner surface of the tube to simulate the welded connection case. See Fig.15.

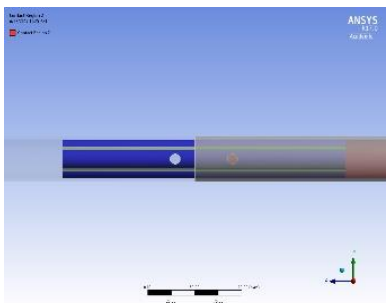

(a) bolted option

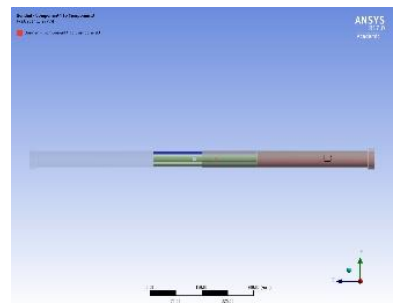

(b) welded option
Fig. 15. The connection between the spigot and the tube where the blue segments represent the welding at all surfaces between the spigot and the tubes and the red circle the contact with the bolts

Five different load cases were considered. For each axial load level, a displacement control was applied. The five axial loads were $0 \mathrm{KN}, 30 \mathrm{KN}$, $60 \mathrm{KN}, 90 \mathrm{KN}$ and $120 \mathrm{KN}$. Since these loads were uniformly distributed, a conversion to axial pressure was undertaken.

For example, the axial pressure for the $30 \mathrm{KN}$ force is given in $\mathrm{Eq} 3$.

$\sigma=\frac{\text { Force }}{\text { Area }}=\frac{30}{\pi \times\left(50^{2}-48.5^{2}\right) / 4}=258 \mathrm{MPa}$

Table 5 shows the axial pressure applied at the end of the system.

Table 5

Pressures applied for different axial loads

\begin{tabular}{ll}
\hline Load $(\mathbf{k N})$ & Pressure $(\mathbf{M P a})$ \\
\hline 0 & Free displacement \\
30 & 258.53 \\
60 & 517.05 \\
90 & 775.58 \\
120 & 1034.10 \\
\hline
\end{tabular}

The transverse loading was applied in the middle of the system by a displacement control in the y axis. A ramp function was applied in the $y$ direction fixing the $\mathrm{x}$ and $\mathrm{z}$ direction. The maximum displacement was chosen such that the maximum ultimate strength was attained during the time frame of the simulation.

A static structural analysis was performed in ANSYS Workbench. The geometry developed using SolidWorks was imported and the material properties as defined above were assigned to the corresponding parts. The aforementioned boundary conditions and loads were input into the ANSYS model to obtain the desired results.

The analysis was carried out for zero compression and a mesh sensitivity was undertaken until convergence occurred. Simulations were conducted when the total deformation and maximum stresses converged to less than $3 \%$. The convergence was reached when the edge length was $4 \mathrm{~mm}$.

Fig. 16 displays the resulting stress for the bolted connection and Fig. 17 shows corresponding results for the welded connection.

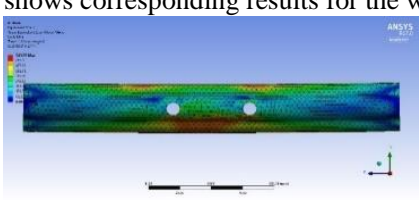

(a) lateral displacement with no axial force

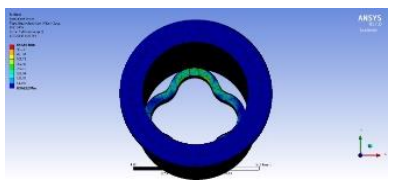

(c) cross -sectional stress with no axial load

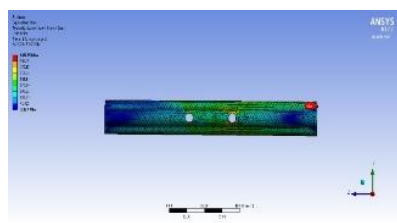

(e) equivalent stress at $30 \mathrm{kN}$ axial load

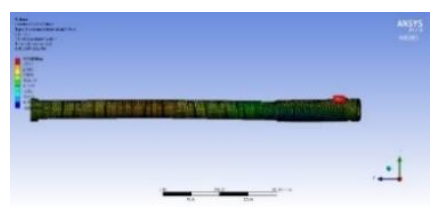

(g) lateral displacement at $60 \mathrm{kN}$ axial load

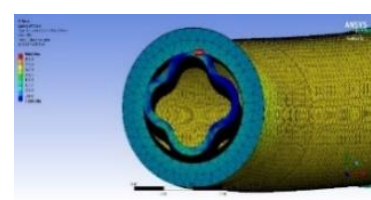

(i) cross-sectional stress at $60 \mathrm{kN}$ axial load

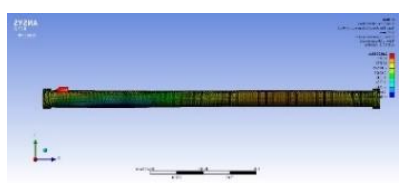

(k) equivalent stress at $30 \mathrm{kN}$ axial load

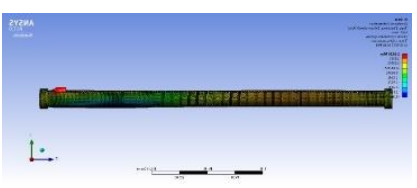

(m) lateral displacement at $120 \mathrm{kN}$ axial load

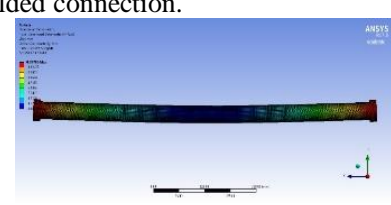

(b) equivalent stress with no axial force

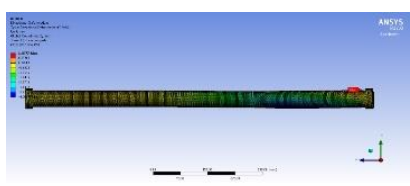

(d) lateral displacement at $30 \mathrm{kN}$ axial load

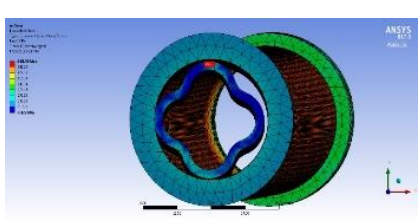

(f) cross-sectional stress at $30 \mathrm{kN}$ axial load

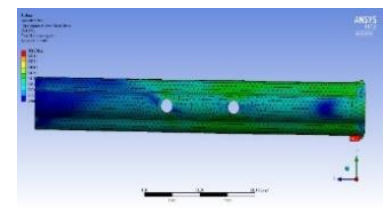

(h) equivalent stress at $60 \mathrm{kN}$ axial load

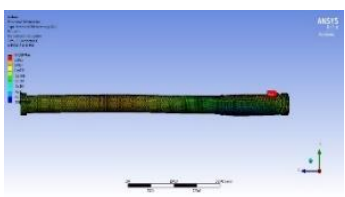

(j) lateral displacement at $90 \mathrm{kN}$ axial load

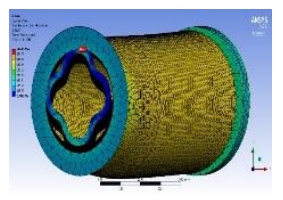

(1) cross-sectional stress at $30 \mathrm{kN}$ axial load

(n) equivalent stress at $120 \mathrm{kN}$ axial load
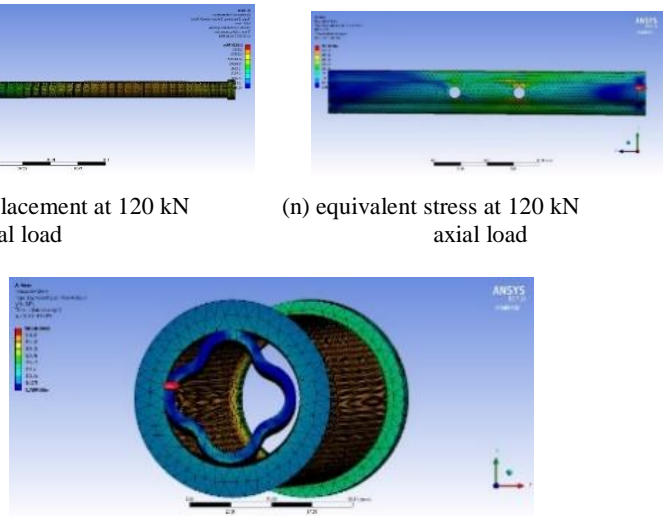

(o) cross-sectional stress at $120 \mathrm{kN}$ axial load

Fig. 16. Plots of displacement and stress for the double bolted connection under different axial load 


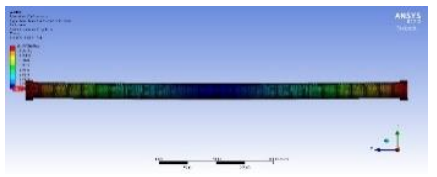

(a) lateral displacement with no axial load

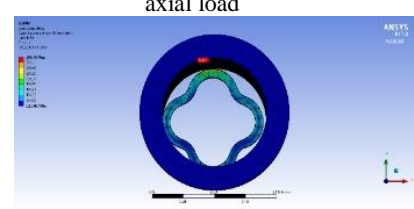

(c) cross -sectional stress with no axial load

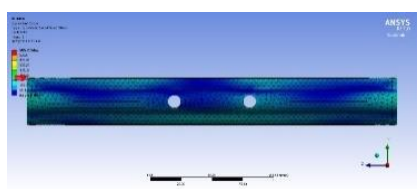

(e) equivalent stress at $30 \mathrm{kN}$ axial load

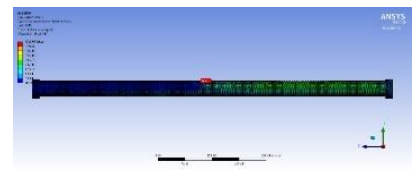

(g) lateral displacement at $60 \mathrm{kN}$ axial load

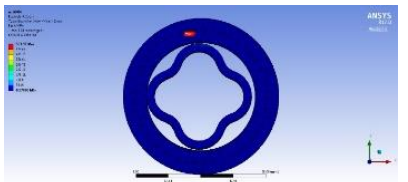

(i) cross-sectional stress at $60 \mathrm{kN}$ axial load

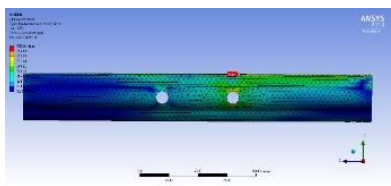

(k) equivalent stress at $30 \mathrm{kN}$ axial load

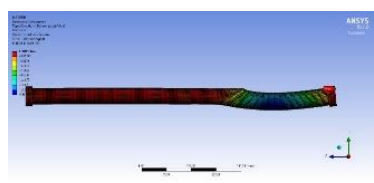

(m) lateral displacement at $120 \mathrm{kN}$ axial load

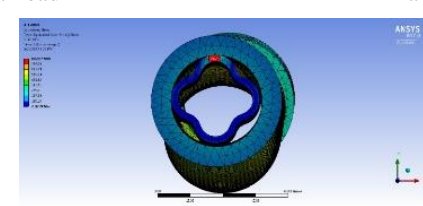

(o) cross-sectional stress at $120 \mathrm{kN}$ axial load

Fig. 17. Plots of displacement and stress for the spigot connection welded at one end bolted at the other under different axial loads.

\subsection{Finite element results}

The moment-rotation curves for the finite element curves were calculated in exactly the same way as those determined from the experiments i.e. the displacements at 40 and $50 \mathrm{~mm}$ from either side of the centre of the spigot and total rotation of the connection determined. The results are shown in Fig. 18. The analyses were continued until either a convergence fail occurred at a given increment and the load could not be increased or a collapse was observed.

From the curves the initial stiffness of the spigot connection for each axial load was determined by fitting a regression straight line through the data up to the point of maximum applied side moment. The stiffnesses are presented in Table 6 . The program was not accurate enough to be able to obtain two stiffnesses and so a single stiffness was produced. These results show that the stiffness of the double bolted connection was usually less than that of the welded connection but that maximum moments were similar. These moments are attributed to plastic hinge formation in the spigot and crushing at the point where the two standards rotated into contact.

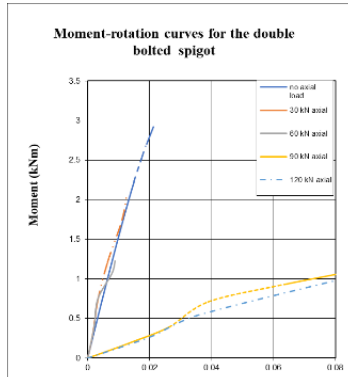

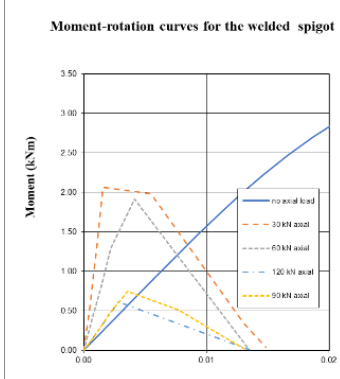

Fig. 18. Moment-rotation curves determined by finite element calculations

Table 6

Initial stiffnesses determined by finite element calculations

\begin{tabular}{lcc}
\hline \multicolumn{1}{c}{ Model Group } & $\begin{array}{c}\text { Initial stiffness } \\
(\mathbf{k N m} / \mathbf{r a d})\end{array}$ & $\begin{array}{c}\text { Maximum } \\
\text { moment }(\mathbf{k N})\end{array}$ \\
\hline Bolted - no axial load & 145.76 & 2.922 \\
Bolted - 30 kN axial load & 165.97 & 2.082 \\
Bolted - 60 kN axial load & 145.14 & 1.227 \\
Bolted - 90 kN axial load & 14.57 & 1.532 \\
Bolted - 120 kN axial load & 12.02 & 1.229 \\
& & 2.914 \\
Welded - no axial load & 148.23 & 2.062 \\
Welded - 30 kN axial load & 1268.17 & 1.917 \\
Welded - 60 kN axial load & & \\
& 497.81 & 0.747 \\
Welded - 90 kN axial load & & \\
& 211.34 & 0.613 \\
Welded - 120 kN axial & & \\
load & 216.30 & \\
\hline
\end{tabular}

\section{Comparisons between theory and experiment}

Both theory and experiment show that the maximum moment that the connections can carry decreases with increasing axial load. In general, the stiffness of the welded connection is higher than that of the bolted connection. The ANSYS program was not able to model the looseness but as Table 3 shows the looseness is in general small with a double bolted connection having twice the looseness of the welded connection. The authors would recommend applying a looseness of approximately 0.009 radians for the double bolted connection, except for the case where there is no axial load where higher values should be used and 0.005 radians for the welded connection. The large variations in the looseness found in the experiments are due to the fact that the connections are manufactured with large tolerances, particularly so that the spigot can easily go into the tubes. In addition, the cutting of tubes to get different tubes was not perfect and often had a burr. This means that frequently the two tubes do not have a perfect join but that the looseness shown in Fig. 2 occurs, a and this affects the performance of the connection.

The initial stiffnesses of the double bolted connections determined experimentally were lower than those determined by the FEA for the cases of $1 \mathrm{kN}, 30 \mathrm{kN}$ and $60 \mathrm{kN}$. This is attributed to effects of looseness and to the accuracy of the FE simulation. For the double bolted and welded connections the FE analysis showed that the statistical result described by André [19, 20] that stiffnesses were unchanged over a range of axial loads and that there were step changes in stiffness at high axial loads. This result mirrored the experimental results although there was significant scatter in the experiments, especially at high axial loads.

The experiments showed a general reduction in moment capacity with increased axial loads. There was good agreement at low axial loads between $\mathrm{FE}$ and experimental maximum loads. 


\section{Conclusions}

A combined experimental and theoretical analysis of spigot connections used to enable the tubes used scaffold and falsework structures to be joined together has been conducted. Reasonable agreement has been made between an ANSYS model of the connection and experimental studies. Two types of connection were tested. Firstly, a set where the spigot insert between the two tubes was bolted two both tubes and secondly where the spigot connection was bolted at one end and spliced at the other end.

Previous studies by other researchers have ignored looseness and this paper presents some results for the first time, namely for the double bolted connection that the looseness was approximately 0.009 radians and for the connection with one end welded and the other bolted was 0.005 radians.

The experiments and the FE calculations showed that at high axial loads that such connections are unstable and can only take a limited amount of side moment.

The theoretical and experimental procedures have validated André's statistical model $[19,20]$ that for a large range of axial loads the rotational stiffnesses can be considered constant but there are differences at low and high axial loads.

\section{Acknowledgements}

The authors would like to thank The University of Jordan for funding the experiments and Oxford Brookes University for providing the facilities to enable the experiments to be conducted.

\section{References}

[1] Bragg S.L., "Final report of the Advisory Committee on Falsework", Her Majesties Stationary Office, London, 1975.

[2] BS 5975, "Code of practice for falsework", British Standards Institution, London, UK, 1996.

[3] Lightfoot E. and Le Messurier A., "Instabilty of space frames having elasticallyconnected and offset members". Proceedings of the Second International Conference on Space Structures, Guildford, UK, 143-149, 1977.

[4] Lightfoot E. and Oliveto G., "The collapse strength of tubular steel scaffold assemblies", Proceedings of the Institution of Civil Engineers, 63, 311-329, 1977.

[5] Beale R. G., "Scaffold research - a review", Journal of Constructional Steel Research, 98(1), 188-200, 2014.

[6] Beale E. and André J., "Design solutions and innovations in temporary structures", IGI Global, Hershey, PA, USA, 2017.

[7] BS EN 12811-1:2003, “Temporary works equipment, Part 1: scaffolds-performance requirements and general design", British Standards Institution, London, UK, 2003.

[8] BS EN 74-1, "Couplers, spigot pins and baseplates for use in falsework and scaffolds Part 1: couplers for tubes - requirements and test procedures", British Standards Institution, London, UK, 2005.

[9] Abdel-Jaber M.S., Beale R.G., Godley M.H.R. and Abdel-Jaber M., "Rotational strength and stiffness of tubular scaffold connectors", Proceedings of the Institution of Civil Engineering Structures and Buildings, 162, 391-403, 2009.

[10] Prabhakaran U., Beale R.G. and Godley M.H.R.G., "Analysis of scaffolds with connections containing looseness", Computers and Structures, 89, 1944-1955, 2011.

[11] Cimellaro G.P. and Domaneschi M., "Stability analysis of different types of steel scaffolds", Engineering Structures, 152, 535-548, 2017.

[12] Sevim B., Bekiroglu S and Arsan G., "Experimental evaluation of tie-bar effects on structural behaviour of suspended scaffold systems", Advanced Steel Construction - an International Journal, 13, 62-77, 2017.

[13] Peng J.L., Ho C.M., Chan S.L. and Chen W.F., "Stability study on structural systems assembled by system scaffolds", Journal of Constructional Steel Research, 137, 135-181, 2017.

[14] Peng J.L, Wang C.S., Wu C.W. and Chen W.F., "Experiment and stability analysis on heavy-duty scaffold systems with top shores", Advanced Steel Construction - an International Journal, Advanced Steel Construction - an International Journal, 13, 293$317,2017$.

[15] Liu H., Wen S., Liu Q., Wang G. and Chen Z., "Experimental and theoretical studies on the stability of steel tube-coupler scaffolds with different connection joints", Engineering Structures, 106, 80-95, 2016.

[16] Milojkovic, "Factors of safety for standard scaffold structures", PhD Thesis, Oxford Brookes University, Oxford, UK, 1999.

[17] Beale R.G. and Godley M.H.R., "Numerical modelling of tube and fitting access scaffold systems", Advanced Steel Construction - an International Journal, 2, 199-223, 2006.

[18] Beale R.G. and Godley M.H.R., "The analysis of scaffold structures using LUSAS", Proceedings of LUSAS 95, Tewkesbury, UK, 10-24, 1995.

[19] Godley M.H.R., Beale R.G. and Feng X., "Rotational stiffnesses of semi-rigid baseplates", Proceedings of the fourteenth International Speciality Conference on ColdFormed Steel Structures, St. Louis, USA, 323-334, 1998.

[20] BS EN 15512:2009, "Steel static storage systems - adjustable pallet racking systems principles for structural design", British Standards Institution, London, UK, 2009.

[21] André J., "Determination of the main parameters affecting the performance of bridge falsework systems", PhD Thesis, Oxford Brookes University, Oxford, UK, 2014.

[22] André J., Beale R.G. and Baptista A.M., "Experimental and theoretical investigation of Cuplok ${ }^{\circledast}$ Spigot Connections, Proceedings of the eighth International Conference on Steel and Aluminium Structures ICSAS 2016, Hong Kong, 49, 16, 2016.

[23] Chandrangsu T. and Rasmussen K.J.R., "Full-scale tests and advanced structural analysis of formwork assemblies", Proceedings of the sixth International Conference on Advances in Steel Structures, Hong Kong, 1083-1090, 2009.

[24] Chandrangsu T. and Rasmussen K.J.R., "Structural modelling of support scaffold systems", Journal of Constructional Steel Research, 67, 866-875, 2011.

[25] Enright J., Harris R. and Hancock G.J., "Structural stability of braced scaffolding and formwork with spigot joints", Proceedings of the fifteenth International Speciality Conference on Cold-Formed Steel Structures, Orlando, USA, 357-376, 2000.

[26] BS EN 12811-3:2002, "Temporary structures equipment - Part 3: load testing", British Standards Institution, London, UK, 2012

[27] Prabhakaran U., "Nonlinear analysis of scaffolds with semi-rigid connections", $\mathrm{PhD}$ Thesis, Oxford Brookes University, Oxford, UK, 2011

[28] Blackmore P.A., "The history of wind damage in the UK", Proceedings of the Conference into Wind Loading on Temporary Structures, Buxton, UK, 17-32, 1994.

[29] National Access and Scaffolding Confederation (NASC), "NASC TG20:13: Guide to Good Practice for Scaffolding with Tubes and Fittings", London, UK, 2013.

[30] GB/T/1591-2008, "High Strength Low Alloy Structural Steel", National Standards of the Peoples Republic of China, 2009

[31] ANSYS, “ANSYS Customer Support”, http/www.ANSYS.com, accessed 26 June 2017. 